\title{
FMCW Radar İle Endüstriyel Uygulamalarda Mesafe Ölçüm
}

\author{
Hasan Güz ${ }^{1 *}$, Levent Civcik $^{2}$, Süleyman Canan ${ }^{3}$ \\ ${ }^{1 *}$ Konya Teknik Üniversitesi, Elektrik Elektronik Mühendisliği Bölümü, Konya, Türkiye (ORCID: 0000-0002-1776-6016) \\ ${ }^{2}$ Konya Teknik Üniversitesi, Teknik Bilimler MYO/Bilgisayar Teknolojileri, Konya, Türkiye (ORCID: 0000-0002-4580-8164) \\ ${ }^{3} R \& D$ Director / Elfatek Electronic Ltd., Turkey (ORCID: 0000-0001-5842-5683)
}

(2nd International Conference on Computer, Electrical and Electronic Sciences ICCEES 2021, September 1-3, 2021)

(DOI: $10.31590 /$ ejosat.1004732)

\begin{abstract}
ATIF/REFERENCE: Güz, H., Civcik, L. \& Canan, S. (2021). FMCW Radar İle Endüstriyel Uygulamalarda Mesafe Ölçüm. Avrupa Bilim ve Teknoloji Dergisi, (30), 44-47.

Öz

Endüstride bulunan fabrikalarda aynı hat üzerinde birden çok köprüsü olan vinçler bulunmaktadır. Bu köprüler aynı yolda hareket ederken her biri başka operatör tarafından kontrol edilmektedir. Operatörler taşıdıkları yükü kontrol ederken aynı zamanda köprünün kontrolünü sağlayamayabilirler. Bu nedenle iki vinç köprüsünün birbiri ile çarpışma ihtimali vardır. Bu durumda meydana gelebilecek kazaların önüne geçebilmek için bir sisteme ihtiyaç vardır. Bu sistemin, iki vinç arası mesafeyi ölçmesi ve belirlenen sınır noktaya ulaştığında operatörleri uyarması gerekmektedir. Bu ihtiyacı karşılamak için FMCW(Frequency Modulated Continuous Wave, Frekans Modülasyonlu Sürekli Dalga) Radar tasarımı önerilmiştir. FMCW radarlar, $77 \mathrm{GHz}$ modülasyon frekansında çalışabilen düşük güç ile yüksek çözünürlük ve doğrulukta; hız, açı ve mesafe ölçümü yapan askeri ve endüstriyel çözümler sunmaktadır. Diğer radar tiplerinde olduğu gibi FMCW radarların da en önemli bölümü karşısındaki engele elektromanyetik sinyal gönderecek olan alıcı-verici antenlerdir. Bu çalışmada FMCW radarlar için anten olarak mikroşerit yama dizi anten tasarımı kullanılmıştır. Bunun sebebi daha yüksek anten kazancına sahip olması, az yer kaplaması, düşük güç tüketimi ve bir ışıyıcının arızalanması durumunda dizideki diğer antenler sayesinde sistemin çalışmaya devam edebilmesidir. Bu araştırmalar sonucunda 100 metre ölçüm mesafesi olan bir FMCW radarın maliyetinin düşürülmesi ve üretiminin kolay olması ile birlikte endüstride yaygınlaşabilecek seviyeye geldiği gösterilmiştir.
\end{abstract}

Anahtar Kelimeler: FMCW Radar, Köprü Vinci

\section{Measuring Industrial Distance With FMCW Radar}

\begin{abstract}
Factories in the industry have cranes with multiple bridges on the same line. Each of these bridges is controlled by another operator while moving on the same road. Operators may not be able to control the bridge while controlling the load they carry. Therefore, there is a possibility that two crane bridges will collide with each other. In this case, a system is needed to prevent accidents that may occur. This system is required to measure the distance between the two cranes and alert operators when they reach the designated limit point. To meet this need, FMCW (Frequency Modulated Continuous Wave) Radar design has been proposed. FMCW radars offer military and industrial solutions that measure speed, angle and distance with high resolution and accuracy with low power that can operate at 77 $\mathrm{GHz}$ modulation frequency. As with other types of radar, the most important part of FMCW radars is the transceiver antennas that will send an electromagnetic signal to the opposite obstacle. In this study, microsherite patch array antenna design was used as the antenna for FMCW radars. This is because it has higher antenna gain, less space, low power consumption, and if a radiator fails, the system can continue to work thanks to other antennas in the array. As a result of these studies, it has been shown that an FMCW radar with a measurement distance of 100 meters has reached a level that can become widespread in the industry, with its cost reduction and ease of production.
\end{abstract}

Keywords: FMCW Radar, Overhead Crane

\footnotetext{
${ }^{1}$ Sorumlu Yazar: hasan.guz@elfatek.com.tr
} 


\section{Giriş}

Son yıllarda iş sağlığı ve güvenliği uygulamaları vinç sektöründe çok daha fazla önemsenmeye başlamış olup, özellikle çarpışma önleme sistemleri açısından ön plana çıkmıştır. Aynı sistemde birden fazla - her biri başka operatör tarafindan kontrol edilen - vincin birbiri ile çarpışarak büyük çaplı hasarlara yol açmasını önlemek için çarpışma önleme sistemleri kullanılmaktadır. Vinçlerin çalıştığı ortam şartlarının temiz olduğu işletmelerde fotoelektrik veya lazer sensörler kullanılmaktadır. 1 veya 2 röle çıkışına sahip bu sensörler ile vinçler çarpışmadan önce güvenli kabul edilen mesafelerde yavaşlatılmaya başlanır ve istenen mesafeye geldiklerinde durdurulur. Aşırı tozlu, buharlı, kirli, yağlı ortamlarda ve açık hava şartlarında bu sayılan sensörler bozularak vinç çarpışmasını önleyememektedir. Bu gibi ağır şartlar altında FMCW radar kullanılarak bu sorunların ortadan kalkması beklenmektedir.

FMCW radarlar, 2. Dünya Savaşı'ndan önce darbeli radarların daha sık kullanılmasından dolayı çoğunlukla uçak irtifası ölçmek için kullanılmıştır [1]. Teknolojideki gelişmeler sonucunda, FMCW radarların yüksek çözünürlüğe, düşük iletim gücüne, daha basit bir yapıya ve düşük hata oranına sahip olmasından dolayı günümüzdeki kullanım alanlarını genişletmiş̧ir[2]. Literatürde FMCW radarlar sivil ve askeri alanlar başta olmak üzere birçok farklı alanlarda kullanıldığı görülmektedir. Bunlardan bazıları, otoyollarda araç hızı ölçümü [3], araç çarpışma uyarı sistemleri [4], yüksek gürültü ortamlarda hedef tespitidir [5]. Şekil-1'de FMCW radarın blok diyagramı gösterilmiştir. Sürekli olarak üretilen frekans modüleli (FM) sinyali iletici anten vasitasıyla yayılımı sağlanarak daha sonrasında hedeften-engelden dönen sinyaller alıcı anten tarafindan alınır ve çarpıldıktan sonra hedefin-engelin hizını ve FMCW radara olan mesafesi gibi bilgileri içinde barındıran vuru frekansı $\left(f_{b}\right)$ elde edilir. Son olarak, gerekli sinyal işleme yöntemlerinin uygulanması ile hedefe ait hiz ve mesafe bilgileri elde edilir.

$\mathrm{Bu}$ çalışmada açık veya kapalı alanda bulunan ve üzerinde birden fazla vinç bulunan sistemlerin çarpışmasını önlemek için FMCW radar kullanılması önerilmiştir.

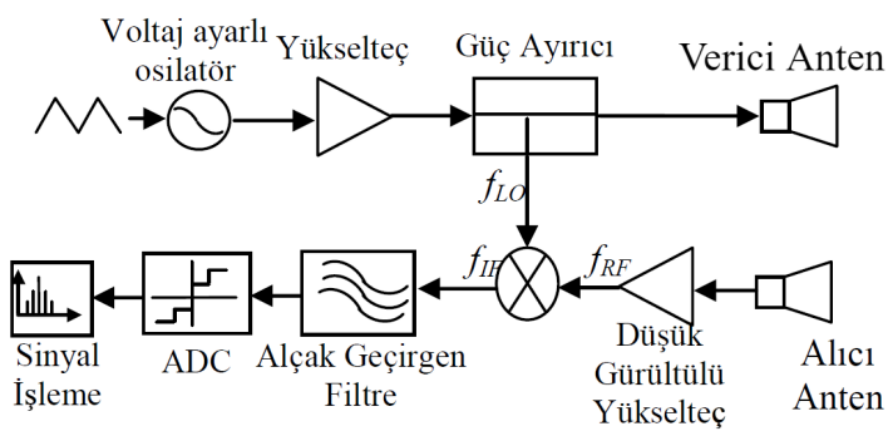

Şekil 1. FMCW Radar blok diyagramı

\section{Materyal ve Metot}

FMCW radarlar önceden büyük ve hantal yapıda oldukları için endüstriyel uygulamalar için tercih edilmemiştir [6]. Günümüzde teknolojinin ilerlemesi ve milimetre dalga radarı üzerine çalışmaların artması ile Şekil-1'de verilen blok diyagramdaki bütün bileşenlerin tümü tek bir elektronik devre kartında bulunabilir [7]. Bu çalışmada hız, mesafe ve yön bilgilerini verebildiği için AWR1843BOOST FMCW radar kullanılmıştır.

\subsection{AWR1843BOOST FMCW Radar}

Texas Instruments (TI) markasının geliştirdiği AWR1843BOOST cihazı (Şekil-2), 76 ila $81 \mathrm{GHz}$ bandında çalışabilen entegre bir tek çipli FMCW radar sensörüdür. Dahili PLL (phase-locked loop, faz kilitlemeli çevrim) ve analogtan dijitale dönüştürücülerle $3 \mathrm{TX}, \quad 4 \mathrm{RX}$ sisteminin monolitik bir uygulamasını sağlayan TI firmasının düşük güç tüketen otomotiv ve endüstriyel alanlarda kullanılmak üzere geliştirdiği bir radar sensördür.

AWR1843BOOST cihazı ile 0-200 metre arası mesafeyi ve Doppler etkisi kullanılarak $0-150 \mathrm{~km} / \mathrm{s}$ arası hızları 120 derece açı ile tespit edilebilmektedir.

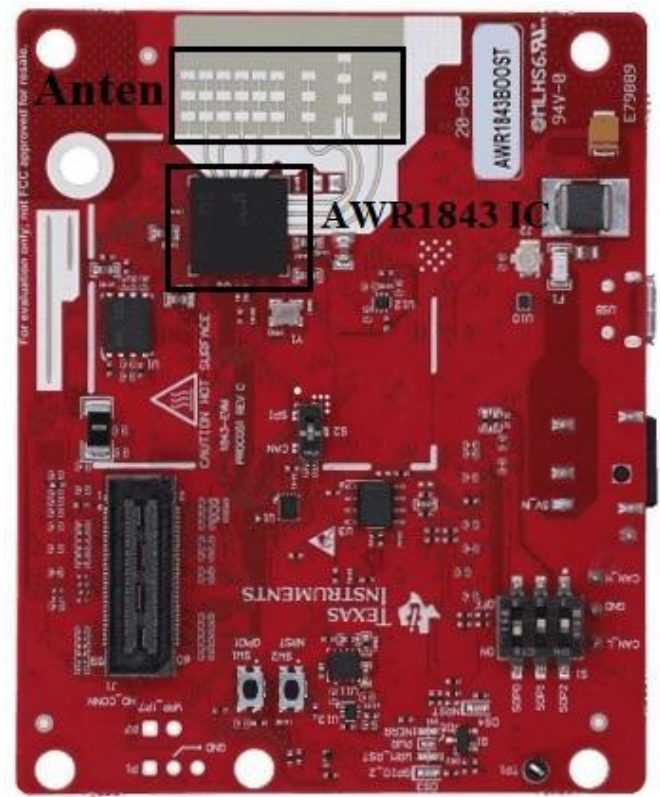

Şekil 2. AWR1843BOOST FMCW Radar

\subsection{FMCW Radar Prensipleri}

FMCW radarı en basit bir sürekli dalga radarında olduğu gibi sürekli dalga yollayan radar sensörlerinin bir özel tipidir. Sürekli dalga radarının aksine, bir FMCW radarı ölçüm yapıldığı sırada üçgen veya testere dişi dalga kullanarak gönderilen işaretin çalışma frekansını değiştirebilir. $\mathrm{Bu}$, gönderim işaretinin frekansının modüle ediliyor olması demektir. İşte frekanstaki bu değişmeler sayesinde işaretlerin gidiş-geliş süreleri ölçümüyle ilk defa ilave ölçüm imkânları ortaya çıkmıştır.

Verici anten vasıtasıyla gönderilen sinyal olası hedeflerden yansiyıp hedefin FMCW radar olan mesafesine bağlı gecikmesiyle alıcı antenle alınmaktadır. Alınan sinyal, gönderilen sinyalin zamanda geciktirilmiş ve frekansta kaydırılmış kopyasıdır. Zaman gecikmesi kullanılarak hedefin FMCW radara olan mesafesi, frekans değişimi kullanılarak da hedefin hızı hesaplanabilmektedir. FMCW radarlarda zaman gecikmesi gönderilen ile alınan sinyallerin anlık frekans farkıyla $\left(f_{b}\right)$ ilişkilidir (Şekil 3): $\Delta \mathrm{t}=\gamma f_{b}$. Dolayısıyla, hedefin menzili $\mathrm{R}=$ $\mathrm{c} \Delta \mathrm{t} / 2=\mathrm{c} \gamma f_{b} / 2$ 'dir. Karıştırıcının çıkışı ise frekansı bu farkla eşit olan bir sinüzoidal sinyaldir. Sinyal bir yükseltici ve alçak geçiren filtre devresinden geçtikten sonra işlenmek üzere bilgisayara aktarılmaktadır. 


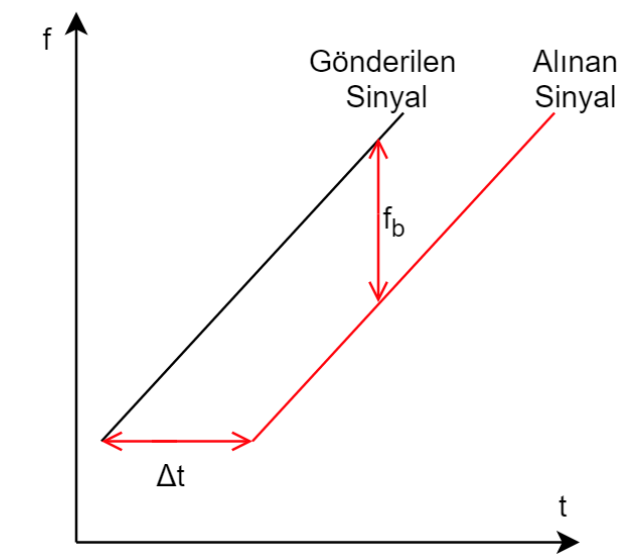

Şekil 3. FMCW Radar sinyalinin frekans-zaman grafiği

\section{Bir FMCW radarın ;}

- Çok kısa mesafelerde dahi ölçüm yeteneği

- Menzil ve hız aynı anda ölçebilme

- Yüksek ölçüm doğruluğu

- Olumsuz çevre koşullarında da çalışabilme gibi temel özellikleri bulunmaktadır.

\subsection{Vinç Çarpışma Önleme Sistemi}

$\mathrm{Bu}$ çalışmada bir sistemde iki vinç olduğu kabul edilmiştir. 2 vincin bulunduğu bir sistem için Şekil-4'deki gibi bir uygulama önerilmiştir. Bu uygulamada DUVAR-VİNÇ 1, VİNÇ 1-VİNÇ 2 ve VINÇ 2-DUVAR çarpışmasını önlemek amaçlanmıştır. Bu sebeple 3 adet FMCW radar yerleştirilmiştir. Radarlar vinçlerin daha önceden verilen güvenlik sınırına (örneğin 2 metre) ulaşıp ulaşmadığını tespit edecektir. Tespit edildiği takdirde vinç hareket sistemine bilgi-uyarı verecektir. Bu bilgi-uyarı geldiğinde röleler yardımı ile vincin durdurulması sağlanacaktır.

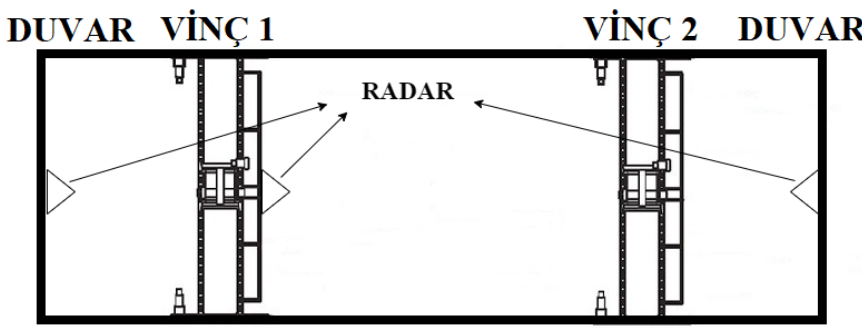

Sekil 4. Önerilen vinç çarpıșma önleme sistemi

Sistemdeki vinç sayısı arttıkça FMCW radar sayısının arttırılması gerekmektedir.

\subsection{AWR1843BOOST FMCW Radar ile Ölçüm}

AWR1843BOOST FMCW radar duvar hizasına sabitlenmiştir. Vinç uzaktan kumanda ile ileri ve geri yönde hareket ettirilmiştir (Şekil-5). Vincin bulunduğu fabrikanın çalışma imkanlarından dolayını 2-50 metre aralığında ölçüm yapılmıştır. Vincin hareketi sonucunda radar dataları TI firmasının geliştirdiği arayüzde görüntülenmiştir. $\mathrm{Bu}$ arayüzde gönderici ve alıcı antenlerden kaçının kullanılacağı, bant genişliği ve radar çıktı çözünürlüğü gibi ayarlar yapılabilmektedir. Şekil-6'da vincin radara yani duvara en yakın olduğu andaki arayüz çıktısı verilmiştir. AWR1843BOOST FMCW radar çalışma frekansından dolayı yüksek çözünürlüğe sahip oldukları için vincin en küçük bir hareketi bile görüntülenebilmektedir.

Menzil ölçümünün yanı sıra vincin h1zı da görüntülenebilmektedir. Bu ileride geliştirilecek otonom vinçler için önemli bir bulgudur.

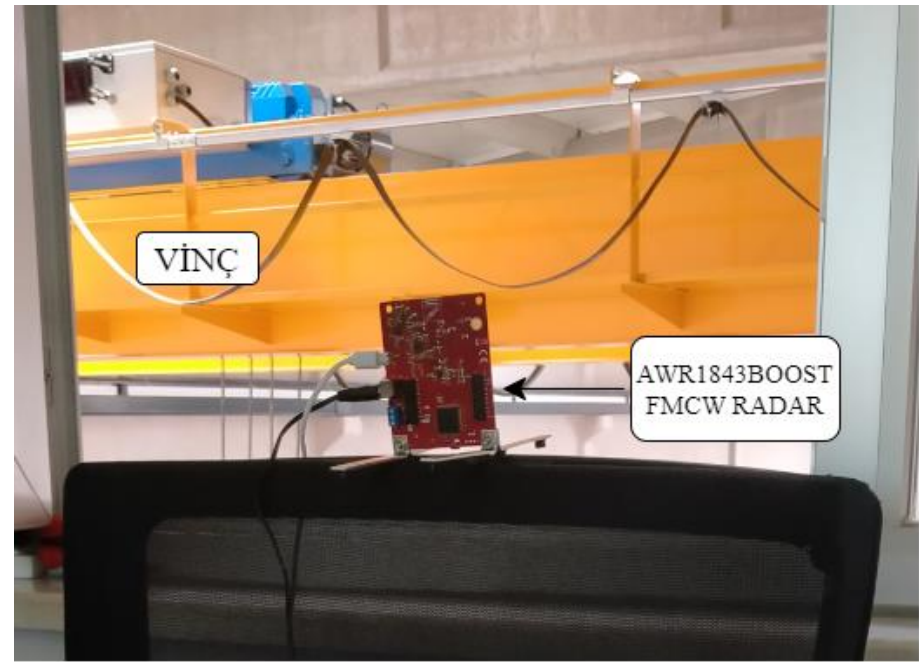

Şekil 5. AWR1843BOOST FMCW radar ile ölçüm

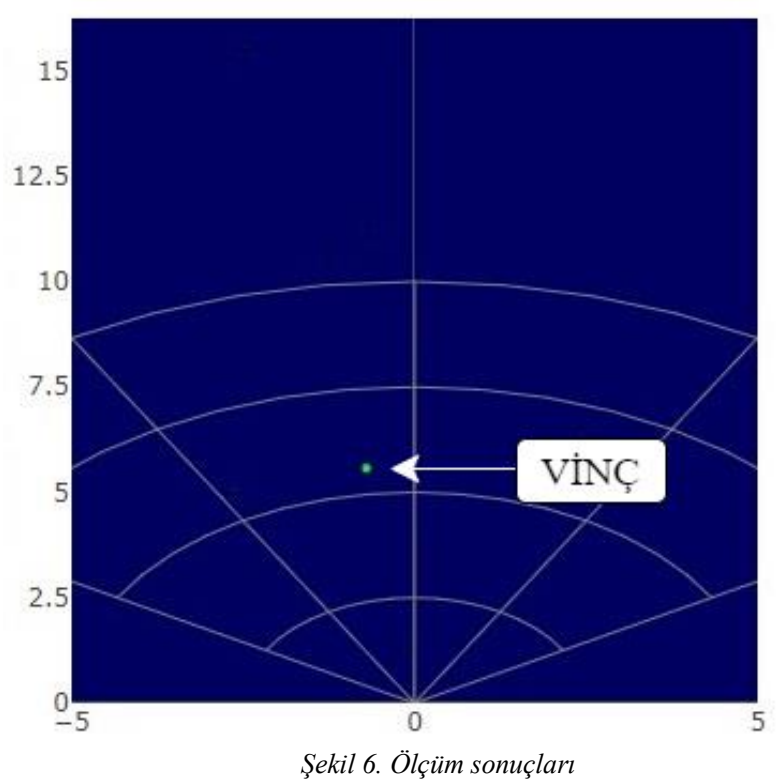

\section{Sonuçlar}

Bu çalışmada tek sistemde birden fazla - her biri başka operatör tarafından kontrol edilen - vincin birbiri ile çarpışmasını önlemek amacı ile FMCW radarlar kullanılarak vinç çarpışma önleme sistemi önerilmiştir. Önerilen sisteme bağlı kalarak endüstriyel üretim yapan bir firmada AWR1843BOOST FMCW radar ile ölçümler yapılmıştır. Yapılan ölçümlerde alınan başarılı sonuçlar neticesinde önerilen sistemin başarılı olacağı görülmüştür. $\mathrm{Bu}$ sonuçlar neticesinde FMCW radarların endüstriyel uygulamalarda başarılı sonuçlar getireceği öngörülmektedir. Gelecekte önerilen sistemin tümüyle gerçeğe dönüştürülmesi hedeflenmektedir.

\section{Teşekkür}

Çalışmanın gerçekleştirilmesi için gerekli olan AWR1843BOOST FMCW radarını tedarik eden ve radar ile ölçüm yapılması için uygun çalışma ortamını oluşturan Elfatek Elektronik Ltd.'e teşekkür ederiz. 


\section{KAYNAKLAR}

[1] K Komarov, I. V. and M. S. Smolskiy, Fundamentals of Short Range FM Radar, Artech House, 2003.

[2] Handayani, D.O.D., W. Sediono and A. Shah"Design and Development of the FMCW Radar Scene Generator," Industrial Electronics and Applications (ISIEA), pp. 39 44,September 2013

[3] Winkler, V.,"Range Doppler Detection for Automotive FMCW Radars," Radar Conference (EuRAD), pp. 166-169, October 2007

[4] Steinhauer, M., H.O. Ruo, H. Irion and W. Menzel" Millimeter-Wave Radar Sensor Based in a Transciever Array for Automotive Applications,"Microwave Theory and Techniques, Vol.56, pp. 261-269, Februray 2008

[5] Duarte, C., P. Dorta, A. Lopez, A.D. Campo,"CWLFM Radar for Ship Detection and Identification," IEEE Aerospace and Electronic Systems Magazine, Vol. 22, pp. 22-26, Februrary 2007.

[6] Andersen, N., Granhaug, K., Michaelsen, J. A., Bagga, S., Hjortland, H. A., Knutsen, M. R., ... \& Wisland, D. T. (2017). A 118-mw pulse-based radar soc in 55-nm cmos for non-contact human vital signs detection. IEEE Journal of Solid-State Circuits, 52(12), 3421-3433.

[7] https://www.ti.com/sensors/mmwave-radar/products.html 